\title{
The Polysomnographs
}

by ${ }^{\circ}$ GRASS

For recording EEG, EMG, EOG, ECG, Heart Rate, Pulse, Respiratory Effort, Oral and Nasal Respiratory Air Flow, Breathing Sounds, Limb Movement, Oximetry, $\mathrm{CO}_{2}$, N.P.T.
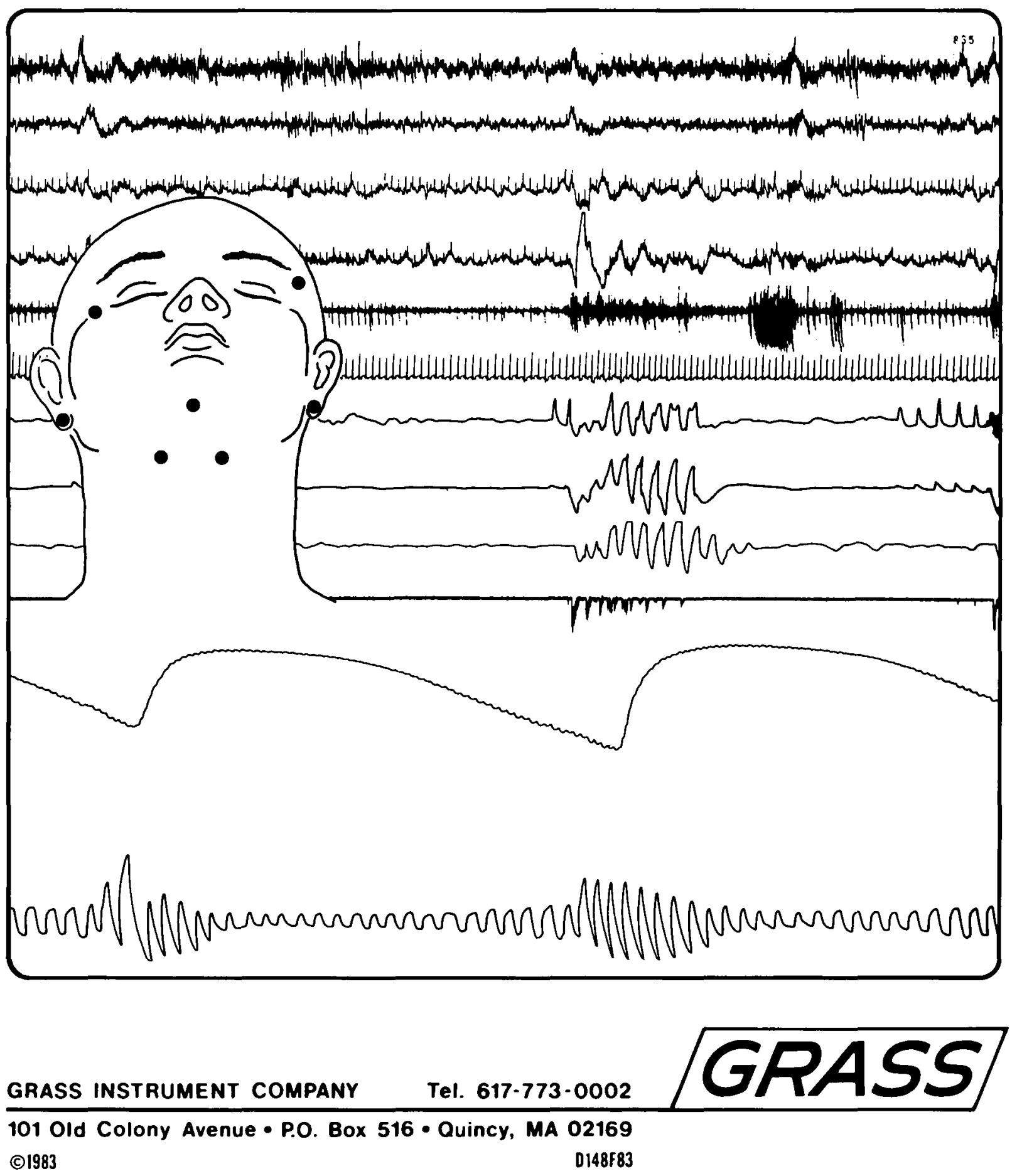


\section{Brief prescribing information}

INDICATIONS AND CLINICAL USE: Depakene (valproic acid) is indicated for use as sole and adjunctive therapy in the treatment of simple and complex absence seizures, including petit mal. Valproic acid may also be used adjunctively in patients with multiple-seizure types which include absence.

In accordance with the International Classification of Seizures, simple absence is defined as a very brief clouding of the sensorium or loss of consciousness (lasting usually 2-15 seconds) accompanied by certain generalized epileptic discharges without other detect
signs. Complex absence is the term used when other signs are also present.

CONTRAINDICATIONS: Depakene (valproic acid) should not be administered to patients with hepatic disease or significant dysfunction; it is contraindicated in patients with known hypersensitivity to the drug.

WARNINGS: Hepatic failure resulting in fatalities has occurred in patients receiving Depakene. These incidences usually have occurred during the first six months of treatment with Depakene. Serious or fatal hepatotoxicity may be preceded by non-specific symptoms such as loss of seizure control, malaise, weakness, lethargy, anorexia and vomiting. Patients and parents should be instructed to report such symptoms. Because of the nonspecific un well, other than through obvious causes while taking sodium valproate.

Liver function tests should be performed prior to therapy and at frequent intervals thereafter especially during the first six months. However, physicians should not rely totally on serum biochemistry since these tests may not be abnormal in all instances, but should also consider the results of careful interim medical history and physical examination. Caution should be observed when administering Depakene to patients with a prior history of hepatic disease. Patients with various unusual congenital disorders, those with severe seizure disorders accompanied by mental retardation, and those with organic brain disease may be at particular risk.

In high-risk patients, it might also be useful to monitor serum fibrinogen and albumin for decrease in concentrations and serum ammonia for increases in concentration. If changes occur, valproic acid should be discontinued. Dosage should be titrated to and maintained at the lowest dose consistent with optimal seizure control.

The drug should be discontinued immediately in the presence of significant hepatic dysfunctions, suspected or apparent. In some cases, hepatic dysfunction has progressed in spite of discontinuation of drug. The frequency of adverse effects particularly elevated live enzymes may increase with increasing dose. Therefore, the benefit gained by increased seizure control by increasing the dosage must be weighed against the increased incidence of adverse effects sometimes seen at higher dosages.

USE IN PREGNANCY: The safety of Depakene (valproic acid) during pregnancy has not physician should weigh the potential benefits against the possible risks in treating or counselling women of childbearing age who have epilepsy.

Recent reports indicate an association between the use of anticonvulsant drugs and an elevated incidence of birth defects in children born to epileptic women taking such medication during pregnancy. The incidence of congenital malformations in the general population is regarded to be approximately $2 \%$; in children of treated epileptic women, this incidence may be increased two to three-fold. The increase is largely due to specific defects, e.g. congenital
malformations of the heart, and cleft lip and/or palate. Nevertheless, the great majority of mothers receiving anticonvulsant medications deliver normal infants.

Data are more extensive with respect to diphenylhydantoin and phenobarbital, but these drugs are also the most commonly prescribed anticonvulsants. Some reports indicate a possible similar association with the use of other anticonvulsant drugs, including trimethadione and paramethadione. However, the possibility also exists that other factors e.g. genetic predisposition or the epileptic condition itself may contribute to or may be mainly responsible for the higher incidence of birth defects.

Anticonvulsant drugs should not be discontinued in patients to whom the drug is administered to prevent major seizures, because of the strong possibjlity of precipitating status epilepticus with attendant hypoxia and risks to both the mother and the unborn child. With regard to drugs given for minor seizures, the risks of discontinuing medication prior to or during pregnancy should be weighed agair

Epileptic women of child-bearing age should be encouraged to seek the counsel of their physician and should report the onset of pregnancy promptly to him. Where the necessity for continued use of antiepileptic medication is in doubt, appropriate consultation might be indicated.

NURSING MOTHERS: Depakene is secreted in breast milk. Concentrations in breast milk have been reported to be 1 to $10 \%$ of serum concentrations. As a general rule, nursing should not be undertaken while a patient is receiving valproic acid.

FER TILITY: Chronic toxicity studies in juvenile and adult rats and dogs demonstrated reduced spermatogenesis and testicular atrophy at doses greater than $200 \mathrm{mg} / \mathrm{kg} /$ day in rats and $90 \mathrm{mg} / \mathrm{kg} /$ day in dogs. Segment I fertility studies in rats have shown that doses up to 350 $\mathrm{mg} / \mathrm{kg} /$ day for 60 days have no effect on fertility. The effect of Depakene (valproic acid) on the development of the testes and on sperm production and fertility in humans CARCINOGENIC RISK.

PRECAUTIONS: HEPATIC DYSFUNCTION: SEE CONTRAINDICATIONS AND WARNINGS

GENERAL: Because of reports of thrombocytopenia and platelet aggregation dysfunction, platelet counts and bleeding-time determination are recommended before instituting therapy and at periodic intervals. It is recommended that patients receiving Depakene (valproic acid) be monitored for platelet count prior to planned surgery. Clinical evidence of hemorrhage.
bruising or a disorder of hemostasis / coagulation is an indication for reduction of Depakene (valproic acid) dosage or withdrawal of therapy pending investigation.

Hyperammonemia with or without lethargy or coma has been reported and may be present in the absence of abnormal liver function tests; if elevation occurs, the valproic acid should be discontinued

Because Depakene (valproic acid) may interact with other anticonvulsant drugs, periodic serum level determinations of such other anticonvulsants are recommended durng the earl part of therapy (see DRUC INTERACTIONS). There have been reports of breakthrough seizures occurring with the combination of Depakene and phenytoin.

Depakene (valproic acid) is partially eliminated in the urine as a ketone-containing metabolite which may lead to a false interpretation of the urine ketone test.

DRIVING AND HAZARDOUS OCCUPATIONS: Valproic acid may produce CNS

depression, especially when combined with another CNS depressant, such as alcohol.

Therefore, patents should be advised not to engage in hazardous occupations, such as
driving a car or operating dangerous machinery, until it is known that they do not become

drowsy from the drug.

DRUG INTERACTIONS: DEPAKENE (VALPROIC ACTD) MAY POTENTIATE THE CNS DEPRESSANT ACTION OF ALCOHOL.

THERE IS EVIDENCE THAT VALPROIC ACID MAY CAUSE AN INCREASE IN SERUM

PHENOBARBITAL LEVELS, ALTHOUGH THE MECHANISM IS UNKNOWN, PATIENTS

RECEIVING CONCOMITANT BARBITURATE THERAPY SHOULD BE CLOSELY

SHOULD BE OBTAINED, IF POSSIBLE, AND THE BARBITURATE DOSAGE DECREASED, IF INDICATED.

Primidone is metabolized into a barbiturate, and therefore, may also be involved in a similar or identical interaction. ACID WITH PHENYTOIN. IT IS NOT KNOWN IF THERE IS A CHANGE IN UNBOUND ACID WITH PHENYTOIN. IT IS NOT KNOWN IF THERE IS A CHANGE IN UNB
(FREE) PHENYTOIN SERUM LEVELS. THE DOSE OF PHENYTOIN SHOULD BE (FREE) PHENYTOIN SERUM LEVELS. THE DOSE OF PHEN THE CONCOMITANT USE OF VALPROIC ACID AND CLONAZEPAM MAY PRODUCE ABSENCE STATUS

Caution is recommended when valproic acid is administered with drugs affecting
coagulation, e.g. acetylsalicylic acid and warfarin (see ADVERSE REACIIONS). ADVERSE REACTIONS: The most commonly reported adverse reactions are nausea vomiting and indigestion. Since Depakene (valproic acid) has usually been used with other anticonvulsants, it is not possible in most cases to determine whether the adverse reactions mentioned in this section are due to valproic acid alone or to the combination of drugs. GASTROINTESTINAL: Nausea, vomiting and indigestion are the most commonly reported side effects at the initiation of therapy. These effects are usually transient and rarely require discontinuation of therapy. Diarrhea, abdominal cramps and constipation have also been reported. Anor

CNS EFFECTS: Sedative effects have been noted in patients receiving valproic acid alone but are found most often in patients on combination therapy. Sedation usually disappears upon reduction of other anticonvulsant medication. Ataxia, headache, nystagmus, diplopia,
asterixis, "spots before the eyes", tremor, dysarthria, dizziness, and incoordination have rarely been noted. Rare cases of coma have been reported in patients who were also on phenobarbital.

DERMATOLOGIC: Transient increases in hair loss have been observed. Skin rash and petechiae have rarely been noted.

ENDOCRINE: There have been reports of irregular menses and secondary amenorrhea in patients receiving Depakene.

PSYCHLATRIC: Emotional upset, depression, psychosis, aggression, hyperactivity and behavioural deterioration have been reported.

MUSCULOSKELETAL: Weakness has been reported.

HEMATOPOIETIC: Thrombocytopenia has been reported. Valproic acid inhibits the second phase of platelet aggregation (see DRUG INTERACIIONS). This may be reflected in altered bleeding time. Bruising, hematoma formation and frank hemorrhage have been reported. Relative lymphocytosis and hypofibrin
eosinophilia have also been reported.

HEPATIC: Minor elevations of transaminases (e.g. SGOT and SGPT) and LDH are frequent and appear to be dose-related. Occasionally, laboratory tests also show increases in serum bilirubin and abnormal changes in other liver function tests. These results may reflect potentially serious hepatotoxicity. (See WARNINGS).

METABOLIC: Hyperammonemia. (See PRECAUTIONS). Hyperglycinemia has been reported and associated with a fatal outcome in a patient with pre-existing nonketotic hyperglycinemia.

PANCREATIC: Isolated reports of pancreatitis in association with valproic acid therapy have been received.

SYMPTOMS AND TREATMENT OF OVERDOSAGE: In a reported case of overdosage with Depakene (valproic acid) after ingesting $36 \mathrm{~g}$ in combination with phenobarbital and

phenytoin, the patient presented in deep coma. An EEG recorded diffuse slowing, compatible with the state of consciousness. The patient made an uneventful recovery.

Naloxone has been reported to reverse the CNS depressant effects of Depakene overdose.

should be used with caution.

As valproic acid is absorbed very rapidly, gastric lavage may be of limited value. General supportive measures should be applied with particular attention to the prevention of hypovolemia and the maintenance of adequate urinary output.

DOSAGE AND ADMINISTRATION: Depakene (valproic acid) is administered orally. The recommended initial dose is $15 \mathrm{mg} / \mathrm{kg} /$ day, increasing at one-week intervals by 5 to 10 $\mathrm{mg} / \mathrm{kg} /$ day until seizures are controlled or side effects preclude further increases.

The maximal recommended dose is $60 \mathrm{mg} / \mathrm{kg} / \mathrm{day}$. When the total daily dose exceeds $250 \mathrm{mg}$, it is given in a divided regimen. A 500 -mg enteric coated capsule may be substituted for two 250-mg capsules.

The frequency of adverse effects (particularly elevated liver enzymes) may increase with increasing dose. Therefore, the benefit gained by increased seizure control must be weighed against the increased incidence of adverse effects.

\begin{tabular}{|c|c|c|c|c|c|}
\hline \multicolumn{6}{|c|}{ Table of Initial Doses by Weight (based on $15 \mathrm{mg} / \mathrm{kg} / \mathrm{day}$ ) } \\
\hline & Weight & $\begin{array}{l}\text { Total Daily } \\
\text { Dose (mg) }\end{array}$ & Nun & er of Cap & $\begin{array}{l}\text { les or } \\
\text { ynup }\end{array}$ \\
\hline $\mathrm{kg}$ & $\mathrm{lb}$ & & Dose 1 & Dose 2 & Dose 3 \\
\hline $\begin{array}{l}10-24.9 \\
25-39.9 \\
40-59.9 \\
60-74.9 \\
75-89.9\end{array}$ & $\begin{array}{r}22-54.9 \\
55-87.9 \\
88-131.9 \\
132-164.9 \\
165-197.9\end{array}$ & $\begin{array}{r}250 \\
500 \\
750 \\
1,000 \\
1,250\end{array}$ & $\begin{array}{l}0 \\
1 \\
1 \\
1 \\
2\end{array}$ & $\begin{array}{l}0 \\
0 \\
1 \\
1 \\
1\end{array}$ & $\begin{array}{l}1 \\
1 \\
1 \\
2 \\
2\end{array}$ \\
\hline
\end{tabular}

As the dosage of valproic acid is raised, blood levels of phenobarbital and/or phenytoin may be affected (see PRECAUTIONS)

Patients who experience G.I. irritation may benefit from administration of the drug with food or by a progressive increase of the dose from an initial low level. Such patients may benefit from administration of the enteric-caated capsule. The capst
chewing to avoid local irritation of the mouth and throat.

AVAILABILITY: Depakene (valproic acid) is available as orange-coloured, soft-gelatin capsules of $250 \mathrm{mg}$ in bottles of 100 capsules (Number 5681; DIN 443840); pale yelow, oval sof 507989 ) and as a red syrup containing the equivalent of $250 \mathrm{mg}$ valproic acid, as the sodium salt, per $5 \mathrm{~mL}$ in bottles of $450 \mathrm{~mL}$ (Number 5682 ; DIN 443832).

Depakene is now available in a 500 -mg enteric-coated capsule.

REFERENCES:

1. BM] editorial, March 3, 1979.

3. Jeavons PM et al: Treatment of generalized epilepsies of childhood and adolescence with sodium valproate. Dev Med Child Neurol 1977; 19:9-25.

4. Wilder BJ: Valproic acid in clinical use: An overview. Proceedings of the Valproic Acid

5. Coulter DL et al: Valproic acid in childhood epilepsy. JAMA 1980; 244 (8): 785-88.
PHARMACEUTICAL PRODUCTS DIVISION ABBOTT LABORATORIES, LIMITED
MONTREAL, CANADA HUP 1 A5
- TM PMAC PAAB 


\section{NEUROPATHOLOGIST TORONTO WESTERN HOSPITAL}

Applications are invited for the position of neuropathologist at the Toronto Western Hospital, a 750 bed institution with a strong clinical and research neuroscience group (Playfair Unit).

Candidates must have, or be eligible for, Canadian certification in neuropathology and be eligible for licensure by the College of Physicians and Surgeons of Ontario.

Preference would be for an individual with a good research background who intends to carry out independent high quality research. The successful candidate would have the opportunity of working with 7 other neuropathologists at the University of Toronto. The position carries with it an academic appointment at the University of Toronto at a rank consistent with the individual's background and experience.

In accordance with Canadian immigration requirements, priority will be given to Canadian citizens and permanent residents of Canada.

Replies should be directed to:

Laurence E. Becker, M.D., F.R.C.P. (C)

Head

Division of Neuropathology

University of Toronto

Toronto General Hospital

Eaton Wing C-4-316

Toronto, Ontario M5G 1L7

\section{NEUROSURGEON BRITISH COLUMBIA CANADA}

A third neurosurgeon is required for a 625 bed (456 acute) hospital in North Vancouver, serving 300,000 people. The hospital is modern and fully equipped with the latest imaging capabilities. Fee for service.

Please apply, enclosing curriculum vitae to:

Dr. W.J. Corbett,

Medical Coordinator and Secretary

to Credentials Committee,

Lions Gate Hospital,

North Vancouver, B.C. V7L 2L7

Applications close October 15, 1983.

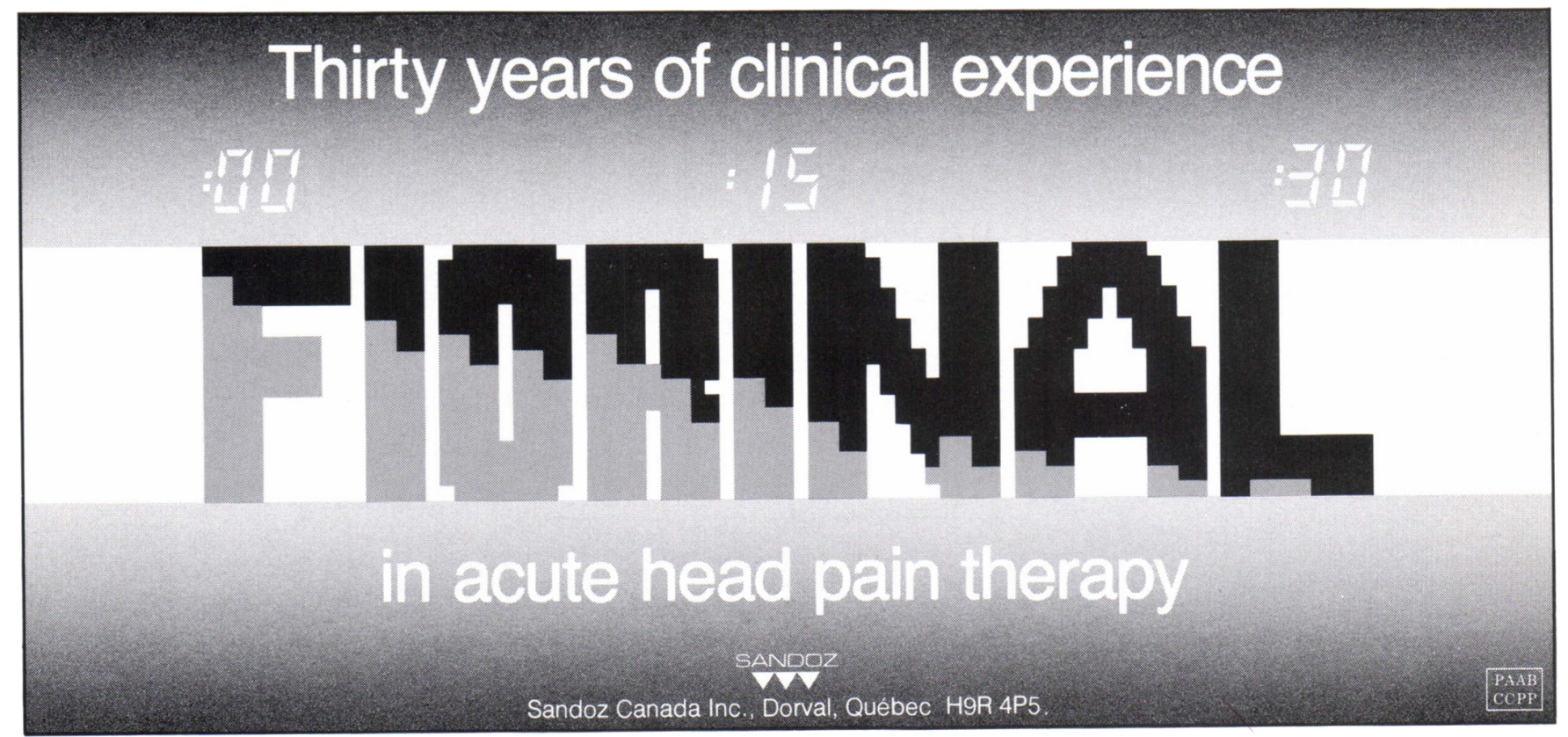

(xi) 


\section{PLioresal $^{\circ}$ \\ (baclofen)}

Muscle relaxant

Antispastic agent

Indications and Clinical Uses

Alleviation of signs and symptoms of spasticity

resulting from multiple sclerosis.

Spinal cord injuries and other spinal cord diseases.

Contraindications

Hypersensitivity to LIORESAL.

Warnings

Abrupt Orug Withdrawal: Except for serious adverse reactions, the dose should be reduced slowly when the drug is discontinued to prevent visual and auditory hallucinations, confusion, anxiety with tachycardia and sweating, insomnia, and worsening of spasticity. Impaired Renal Function: Caution is advised in these patients and reduction in dosage may be necessary. Stroke: Has not been of benefit and patients have shown poor tolerability to the drug.

Pregnancy and Lactation: Nol recommended as safety has not been established. High doses in rats and rabbits are associated with an increase of abdominal hernias and ossification defects in the fetuses.

Precautions

Not recommended in children under 12 as safety has not been established.

Because sedation may occur, caution patients regarding the operation of automobiles or dangerous machinery, activities made hazardous by decreased alertness.

and use of alcohol and other CNS depressants.

Use with caution in spasticity that is utilized to substain upright posture and balance in locomotion, or whenever spasticity is utilized to obtain increased function, pilepsy is histized of obtain increased turclionical

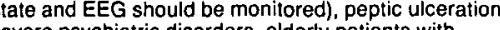
severe psych stric disorders, elderly patients with antihypertensive the

Adverse Reactions

reactions are transient drowsiness, dizziness, weakness and fatigue. Others Neported:

Neuropsychiatric: Headache, insomnia, euphoria, excitement, depression, confusion, hallucinations, paresthesia, muscle pain, tinnitus, slurred speech, coordination disorder, tremor, rigidity, dystonia, ataxia blurred vision, nystagmus, strabismus, miosis,

mydriasis, diplopia, dysarthria, epileptic seizures.

Cardiovascular. Hypo chest pain, syncope.

Gastrointestinal. Nausea, constipation, dry mouth, anorexia, laste disorder, abdominal pain, vomiting. diarthea, and positue test for occull blood in slool. Genitouninary. Urinary frequency, enuresis, urinary retention, dysuria, impol

Other: Rash, pruritus, ankle edema, excessive perspiration, weight gain, nasal congestion. reported may be related to the underlying disease reported may be related io the Ther than to drug therapy.

The lollowing laboratory tests have been found to be abnormal in a few patients receiving LIORESAL: SGOT, Symptoms and Treatment of Overdosage Signs and Symptoms: Vomiting, muscular hypotonia. hypotension, drowsiness, accommodation disorders, coma, respiratory depression, and seizures. Co-administration of alcohol, diazepam, tricyclic antidepressants, etc., may aggravate the symptoms. Treatment: Treatment is symptomatic. In the alert patient, empty the stomach (induce emesis followed by lavage). In the obtunded patient, secure the airway with a cuffed endotracheal tube before beginning lavage (do not induce emesis)

Maintain adequate respiratory exchange; do not use respiratory stimulants. Muscular hypotonia may involve the respiratory muscles and require assisted respiration. Maintain high urinary requt. Dialysis is indicated in severe poisoning associated with renal failure.

Dosage and Administration

Optimal dosage of LIORESAL requires individual titration. Start therapy at a low dosage and increase graduaily until optimum effect is achieved (usually 40-80 mg daily)

The following dosage titration schedule is suggested: $5 \mathrm{mg}$ t.i.d. for 3 days $\quad 15 \mathrm{mg}$ t.i.d. for 3 days $10 \mathrm{mg}$ t.i.d. for 3 days $\quad 20 \mathrm{mg}$ t.i.d. tor 3 days Total daily dose should not exceed a maximum of $20 \mathrm{mg}$ q.i.d.

The lowest dose compatible with an optimal response is recommended. If benefits are not evident after reasonable trial period, patients should be slowly withdrawn from the drug (see Warnings).

Availabillty

LIORESAL (baclofen) $10 \mathrm{mg}$ tablets.

White to off-white flat-faced, oval tablets with GEIGY monogram on one side and the identification code 23 below the monogram. Fully bisected on the reverse

side.

Product Monograph supplied on request

References:

1. Feldman et al, Neurology, Vol. 28, No. 11 pp
$1094-1098,1978$.

2. Symposia Reporter, vol. 3, No. 2.

6.3017

See page iii
MOVING?

PLEASE NOTIFY US OF YOUR CHANGE OF ADDRESS IN ADVANCE.

\section{PASTE OLD ADDRESS LABEL HERE}

NEW ADDRESS:

NAME:

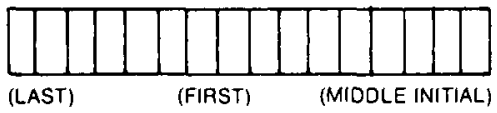

STREET ADDRESS:

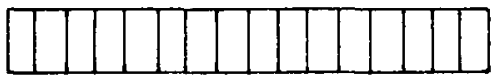

CITY:

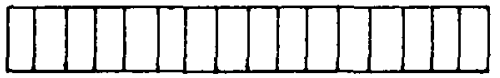

PROVINCE/STATE:

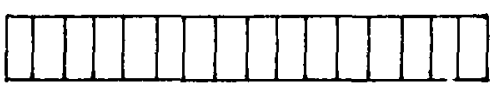

\section{COUNTRY:}

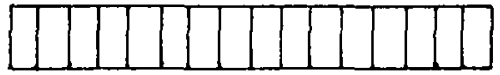

POSTAL/ZIP CODE:

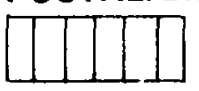

\section{MAIL TO:}

Editor

University of Calgary

Faculty of Medicine

Dept. of Clinical Neuro Sciences

Calgary, Alberta

T2N 4N1

\section{VANCOUVER,}

$$
\text { B.C. }
$$

Opening in private practice for Neurologist, North Vancouver, B.C. E.E.G. and E.M.G. experience essential.

Please contact in writing:

Dr. R.H. Davison,

Department of Neurology,

Lions Gate Hospital,

North Vancouver, B.C.

or phone

(604) 985-1013 (Bus.)

(604) 926-1175 (Home)

\section{ADVERTISER'S INDEX}

Abbott Laboratories Limited

Depakene - IFC, $x$

Disa Electronics Ltd.

Neuromatic - $v$

Geigy

Lioresal - OBC, iii, xii

Tegretol - iv, viii, xiv

Grass Instrument Company

Polysomnographic Recording - ix

Organon Canada Ltd/Ltee.

Hexadrol - IBC, xvi

Sandoz Canada Inc.,

Fiorinal - $x i, x v$

Sandiomigran DS - vii

Unimed Canada Inc.,

Serc - vi 


\section{Together,we can make his world a whole lot safer.}

Today, you help him through life's little hurts. Just as you did with his mom when she was growing up.

Now, you can help him to be free of fear from one of life's big hurts by giving generously to the Canadian Cancer Society in your Will.

It's simple and easy. But the results are heartwarmingly effective.

Strides are being made in the fight against cancer, and your bequest will ensure that important but expensive research will be maintained.

Please make that bequest today. With your Will and our way... together we can make their world a whole lot safer.

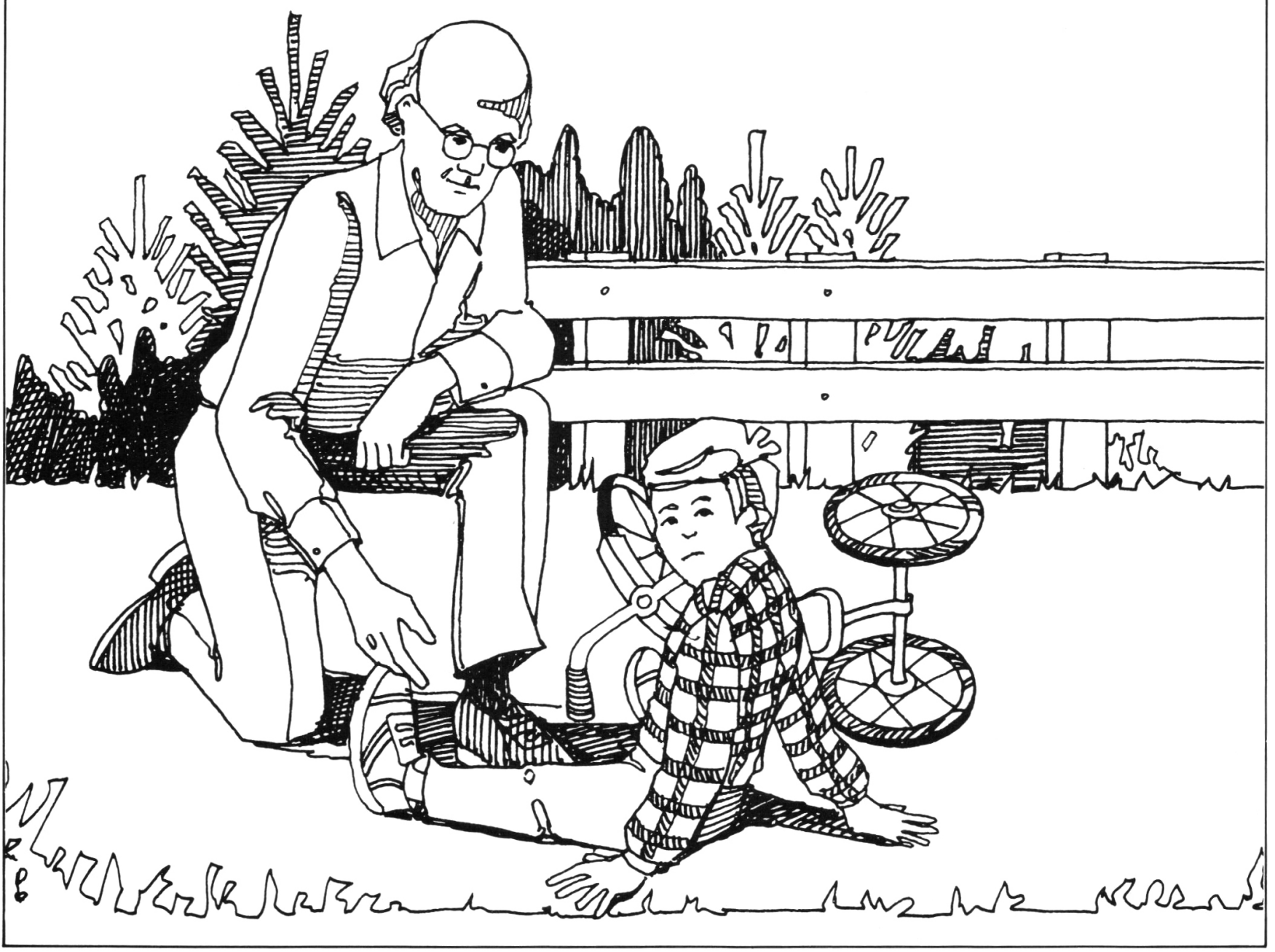




\section{in the efiective}

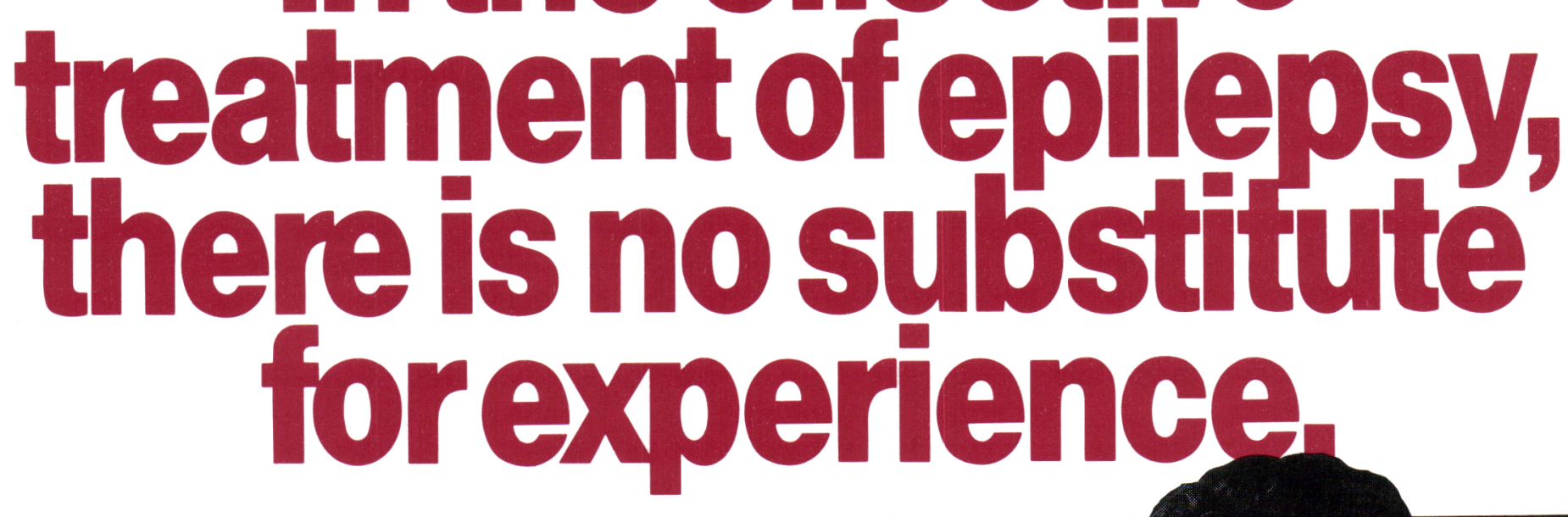

The original carbamazepine, TEGRETOL ${ }^{\circledR}$, was first introduced by Geigy in 1969 and subsequently became the drug of choice for trigeminal neuralgia.

But this development marked only the beginning.

Geigy research soon provided the basis for approval in the treatment of psychomotor/ temporal lobe epilepsy in 1973.

And in 1979, this indication was again expanded to include usage in refractory generalized tonic/clonic seizures.

This committment to the ongoing potential of TEGRETOL does not end here: continuing research indicates that further applications are possible in the future.

While the provision of a quality pharmaceutical is a primary objective of Geigy, other services to both doctor and patient have not gone unaddressed.

Medical information, support to continuing medical education and attention to the needs of epileptic patients, their families and Associations have been important elements in the overall attention given to this disorder.

In fact, a prescription for TEGRETOL does far more in the fight against epilepsy than just control patient symptoms.

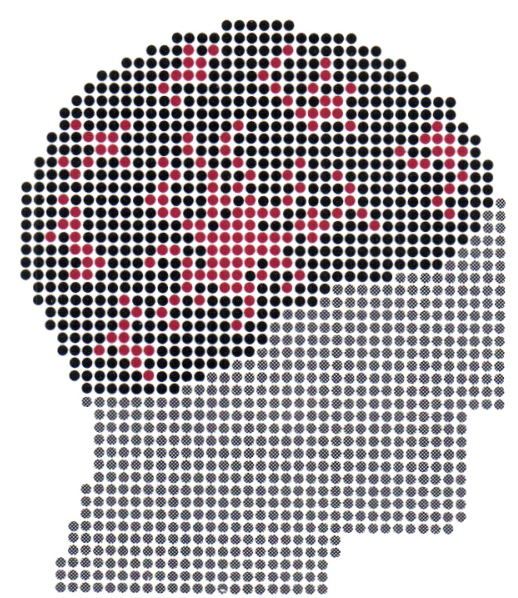

No Substitution.

Because there is no substitute for experience. Yours, or ours. 


\section{this publication is available in microform}

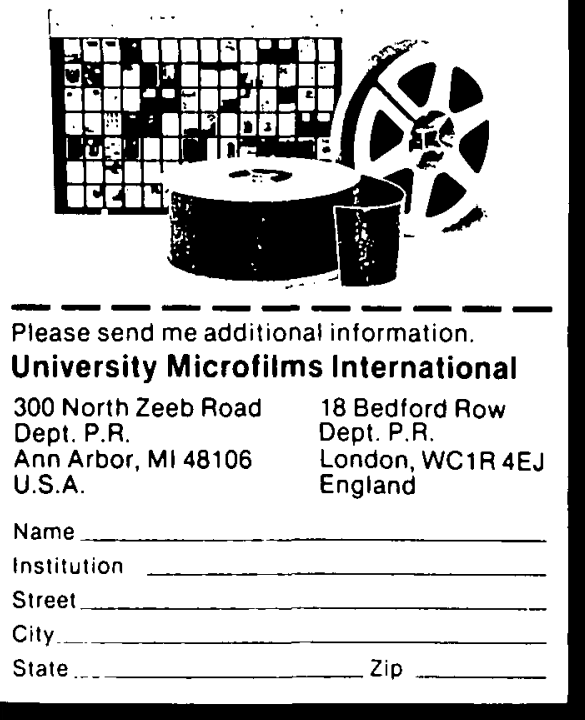

\section{NEUROMUSCULAR FELLOWSHIP}

At least 1 Year, beginning in January or July 1984. Comprehensive experience in Neuromuscular Clinic, including electrophysiological and morphological investigations. Salary through grant support based on research project.

Send curriculum vitae and three references to:

Dr. Charles F. Bolton,

Department of Clinical Neurological

Sciences,

The University of Western Ontario,

Victoria Hospital Corporation,

P.O. Box 5375,

London, Ontario. N6A 4G5

\section{Thirty years of clinical experience}

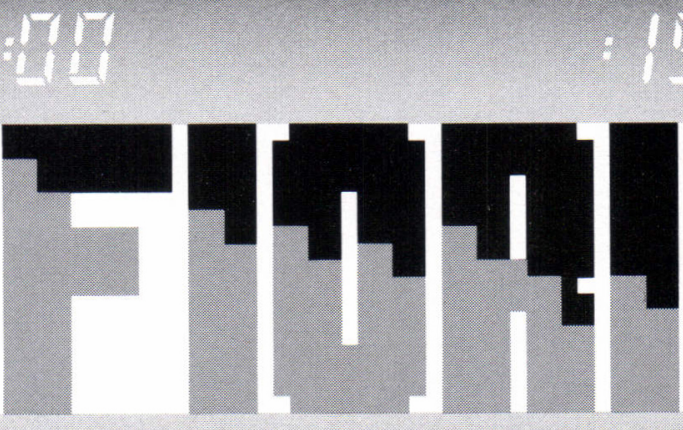

15
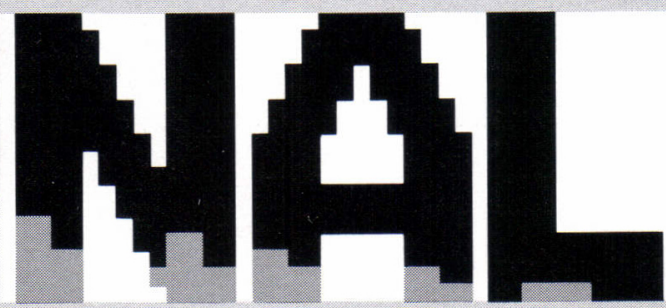

\section{in acute head pain therapy}




\section{Adrenocortical Steroid}

\section{(dexamethasone sodium phosphate injection U.S.P.) PRESCRIBING INFORMATION}

ACTLOHS: Dexamethasone Sodium Phosphate is a synthetic analogue of the naturally-occurring glucocorticoid, hydrocortisone. Glucocorticoids cause protound and varied metabolic effects and are able to modify the body's immune responses to diverse stimuli. Due to the introduction of a 1,2 double bond. a methyl group at carbon 16 , and a fluoride group at carbon 9 , dexamethasone has markedly enhanced
anti-inflammatory and significantly diminished sodium-

IMDICATIOHS: Cerebral edema of diverse etiologies in conjunction with adequate neurological evaluation and management. For a complete list of indications please

CONTRANOICATIONS: Systemic fungal infections; hypersensitivity to any component of the medication.

WARHINGS: In patients on corticosteroid therapy subjected to any unusual stress, increased dosage of rapidly acting
corticosteroids before. during and after the stresstul situation is indicated.

Corlicosteroids may mask some signs of infection and new infections may appear during their use. There may be corticosteroids are and

Prolonged use of corticosteroids may produce posterior subcapsular cataracts. glaucoma with possible damage to secondary ocular intections entue to fungi or viruses.

Corticosteroids should be used cautiously in patients with ocular herpes simplex for fear of corneal ulceration and Ueriora in Pregnancy. Since adequate human reproduction these drugs in pregnancy, nursing mothers or women of the drug be weighed against the potential hazards to the mother and embryo or Tetus. Intants born of mothers who have received substantial doses of corticosteroids during
pregnancy should be carefully observed for signs of hypoadrenalism.

Corticosteroids appear in breast milk and may suppress growth, interfere with endogenous corticosteroid productaking these drugs should be advised not to breastfeed their

Average and large doses of corticosteroids can cause elevation of blood pressure. salt and water retention, and increased excretion of potassium. These effects are less likely 10 occur with the synthetic derivatives except when used in large doses. Dietary salt restriction and potassium
supplementation may be necessary. All corticoster oids
increase calcium excretion.

While on Corticosteroid Therapy Patients Should Not be Vaccinated Against Smallpox. Other Immunization Procedures Should Not be Undertaken in Patients who Are on Corticosteroids, Especially in High Doses, Because of of Antibody Response.
The use of HEXADROL. Phosphate Injection in active tuberculosis should be restricted to those cases of tulminating of disseminated tuberculosis in which the conjunction with appropriate anti-tuberculous regimen. conjunction with appropriate anti-tuberculous regimen. tuberculosis or tuberculin reactivity, close observation is necessary as reactivation of the disease may occur. During
prolonged corticosteroid therapy, these patients should prolonged corticosteroid
receive chemoprophylaxis

Because rare instances of anaphylactoid reactions have occurred in patients receiving parenteral corticosteroid therapy. appropriate precautionary measures should be has a history of allergy to any drug. treated by intravenous injection.

PRECAUTIONS: Drug-induced secondary adrenocortical insufficiency may be minimized by gradual reduction of the dosage. This type of relative insufficiency may persist for months after discontinuation of therapy: therefore, in any situation of stress occurring during that period, hormone secretion may be impaired, salt and/or a mineralocorticoid should be administered concurrently. with porassium-depleting diuretics patients should be observed closely for development of hypokalemia

There is an enhanced effect of corticosteroids in patients with hypothyroidism and in those with cirrhosis.

The lowest possible dose of corticosteroid should be used to control the condition under treatment, and when
reduction in dosage is possible, the reduction must be gradual. antacids be administered between meals to prevent peptic ulcer.
Psychic derangements may appear when corticosteroids are used, ranging from euphoria, insomnia, mood swings personality changes and severe depression to irank bility or psychotic tendencies may be aggravated by

Acetylsalicylic acid should be used cautiously in Steroids should be used with caution in nonspecific ulcerative colitis, if there is a probability of impending perforation, abscess or other pyogenic infection, also in diverticulitis, tresh intestinal anastomoses, active or laten
peptic ulcer, renal insufficiency, hypertension, osteoporosis peptic ulcer, renal insulicien
and myasthenia gravis.

Growth and development of infants and children on
and prolonged corticosteroid therapy should be carefully

Intra-articular injection of a corticosteroid may produce systemic as well as local effects.

joint ifuent intra-aricular injection may result in damage to joint tissues.

Patients should be impressed strongly with the importance of not overusing joints in which symptomatic

Appropriate examination of any joint fluid present is A marked increase in pain. accompanied by local swelling, further restriction of joint motion, fever, and complication occurs and the diagnosis of sepsis is confirmed

local injection of a steroid into a previously infected joint to unstable joints. Corticosteroids should not be injected into Patients who have received prolonged corticoid therapy may develop a state of relative adrenal insufficiency which therapy.

Psychological and/or physiological dependency may develop with long-term use of corticosteroids. Withdrawa symptoms, including anorexia, vague pains, weakness and it may prove litesavir

It may prove lifesaving in critically ill patients suffering severe overwhelming infections for which specific the antibiotic has had time to take effect. Since corticoids mask the classical signs of infection, their use in such cases must be undertaken with the greatest caution. Bacteriological studies and adequate antibiotic therapy must be started before the first dose of this corticoid and its use should be discontinued as soon as possible and at leas Corticosteroids may exacerbate systemic fungal infections and therefore should not be used in the presence of such infections unless they are needed to control drug reactions to amphotericin 8 . Moreover, there have been cases reported in which concomitant use of amphotericin B and congestive tailure.

Diphenylhydantoin phenobarbital, and ephedrine may enhance the metabolic clearance of corticosteroids resulting in decreased blood levels and lessened physiogical activily. Thus requiring adjustment in corticosteroid sone suppression test which should we interpreted with caution during administration of these drugs. should be recognized.

orticosteroids may suppress reactions to skin tests. The prothrombin time should be checked frequently in patients who are receiving corticosteroids and coumarin corticosteroids have altered the response to these been conflicting reports ot por

Injection into the deitoid muscle should be avoided because of the high incidence of subcutaneous atrophy.
In intercostal neuritis and neuralgia, guard against entering the pleura

Overdistention of the joint capsule and deposition of steroid along the needle track should be avoided in intra articular injection since this may lead to tissue atrophy. spermotozoa in some patients. that they have been on corticosteroid therapy.

ADVERSE REACTIONS:

1. Fluid and electrolyte disturbances: sodium retention, fluid retention, congestive heart failure in susceptible patients, potassium loss. hypokalemic alkalosis, hypertension hypotension or shock-like reaction. 2 Musculoskejeta: muscle weakness, steroid myopathy, loss of muscle mass, necrosis of femoral and humeral heads, pathologic fracture of long bones. 3 Gastrolntestinal: peptic ulcer with possible subsequent perntion impaired wound healing thin fragle skin. petechiae an ecchymoses, burning or tingling, especially in the perinea area (after I.V. injection), tacial erythema, increased sweating, may suppress reactions to skin tests, other cutaneous reactions, such as allergic dermatitis, urticaria
angioneurotic edema. 5 Neurological: increased intracrania pressure with papilledema (pseudotumor cerebriy usually menstrual irregularities, dev suppression of growth in children, secondary adrenocort cal and pituitary unresponsiveness, particulary in times o stress, as in trauma, surgery, or illness, decreased
carbohydrate tolerance, manifestations of latent diabetes carbohydrate tolerance, manifestations of latent diabete mypoglycemic agents in diabetics. 7. Ophthalmic: Posterior subcapsular cataracts, increased intraocular pressure glaucoma. exophthalmos. \& Meaboullc. Negative nitrogen Hyperpigmentation or hypopigmentation, subcutaneous
and cutaneous atrophy, sterile abscess, postinjection flare ollowing intra-articular use, charcot-like arthropathy, rare instances of blindness associated with intralesional therap around the face and head, anaphylactoid or hypersensitivity appetite, nausea, malaise, psychological and physiological dependency.

SYMPTOMS AMD TREATMENT OF OVERDOSAGE: DeXamethasone is unlikely to result in acute toxicity due to corticosteroids do not give rise to serious side effects. However, should overdosage occur, there is no known antidote. Gastric lavage should be performed in acute
overdose. Therapy is otherwise symptomatic.

DOSAGE AND ADMINISTRATIO

A. General principles governing administratlon: 1. Dosage disease and the response of the patient. (For intants and children, the recommended dosage will have to be reduced but dosage should be governed by the severity of indicated by age or body weight). 2 . Hormone therapy is an adjunct to, and not a replacement for, conventional therapy. 3 . Dosage must be decreased or discontinued
gradually when the drug has been administered for more than a few days. 4. The severity, prognosis and expected medication are primary factors in determining dosage. 5 . If a period of spontaneous remission occurs in a chronic condition, treatment should be discontinued. 6. Routine laboratory studies such as urinalysis, two-hour post-
prandial btood sugar determination of blood pressure and body weight, and a chest $x$-ray should be made a regular intervals during prolonged therapy. Upper Gl $x-$
rays are desirable in patients with an ulcer history or significant dyspepsia.

B. Intravenous or Intramuscular Injectlon: The usual dose varies from 4 to $20 \mathrm{mg}$ depending on the nature and exceeding $8 \mathrm{mg}$ should be given slowly over a period of one minute. The initial dose may be repeated as necessary until the desire response is average 2 to $4 \mathrm{mg}$ daily. After achieving satisfactory soon as teasible.

In the treatment of unresponsive shock, high pharmacologic doses of glucocorticoids are recommensuggested by different authors. These include: the use of a single intrayenous injection of $1-6 \mathrm{mg} / \mathrm{kg}$. continuous infusion of $3 \mathrm{mg} / \mathrm{kg}$ body weight per 24 hours after initial intravenous bolus of $20 \mathrm{mg}$ and initial intravenous bolus of $40 \mathrm{mg}$ followed by repeated intravenous injecti
shock persists.

Whenever possible use intravenous route for the initial and for as many subsequent doses as are given while the patient is in shock (because of irregular absorption by
other routes in such patients). When the blood pressure responds use the intramuscular route until ora therapy can be substituted.

For the treatment of cerebral edema in adults an initial intravenous dose of $10 \mathrm{mg}$ is recommended, followed by 4 mg intravenously or intramuscularly every 6 hours until then be tapered over several days using either parenteral or oral dexamethasone. Non-operative cases of cerebra edema may require continuous therapy to remain free of symptoms of increased intracranial pressure. The smalest effective dose may be used in children.
preferably orally. This may approximate $0.2 \mathrm{mg} / \mathrm{kg} / 24$
hours in divided doses.

There is a tendency in current medical practice to use high doses of parenter al dexamethasone in the short-term therapy of selected cases of life-threatening cerebral
edema. The following dosage regimens have been edema. The following dosage
suggested by various authors:

Dosage Schedule

Gobiet. et al: Adults: $18 \mathrm{mg}$ as a single dose then $8 \mathrm{mg}$ every 2 hours on days 1 and $3: 4 \mathrm{mg}$ every 2 hours on days 2 and
$4 ; 4 \mathrm{mg}$ every 4 hours on days 5 through 8 . All doses are to be given parenterally.
Children:' age $10-14$ years receive one-half adult dose, age less than 10 years receive one-quarter adult dose. raupel, of al: Adults: $200 \mathrm{mg}$ intravenously followed by 100 mg intramuscularly 6 hours later then, 4 mg intramuscu-
lanly every 6 hours for 8 days, thereatter taper daily by 4 Bruce, at al: Adults and Children: $31.5 \mathrm{mg} / \mathrm{kg}$ as a loading dose followed by $1.5 \mathrm{mg} / \mathrm{kg} /$ day for the first 5 days then
taper slowly over the following 5 days and discontinue.
All doses are to be given parenterally.

Stability studies of HEXADROL: Phosphate Injection diluted in various intravenous solutions in gtass or plastic up to 4 weeks at room temperature.

Patients currently being treated with other glucocorticoids may be conveniently transferred to this agent using the following dosage equivalents: Dexamethasone $-0.75 \mathrm{mg}=$ methylprednisolone and triam cinolone $-4.0 \mathrm{mg}=$ prednisone and prednisol
$\mathrm{mg}=$ hydrocortisone $-20 \mathrm{mg}=$ cortisone $-25 \mathrm{mg}$ SUPPLIED: $5 \mathrm{ml}(4 \mathrm{mg} / \mathrm{ml})$ multiple dose vital (for subcutaneous, intramuscular, or intravenous injection):
$10 \mathrm{ml}(10 \mathrm{mg} / \mathrm{ml})$ multiple dose vial (for intravenous or intramuscular injection only).
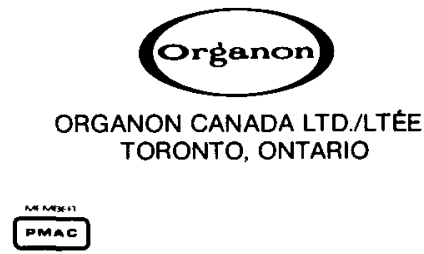

PAAB

-Trademark Registered: Organon Inc.

Registered User: Organon Canada Ltd./Ltée 
In life-threatening head trauma, survival may be measured in milligrams.

Hexadrol $^{\star}$ in high doses increases survival dramatically

While these studies show that even low doses of Hexadrol ${ }^{\star}$ will improve the patient's chance for survival, high doses given quickly are much more beneficial.

Survival rates at increasing dosages of dexamethasone in 2 separate studies

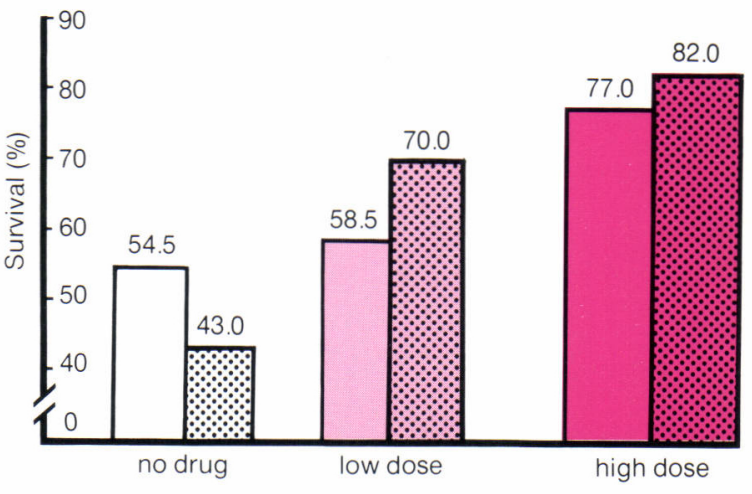

Adapted from

1. Gobiet W et al: Intracranial Pressure III. Edited by Beks JWF et al, Berlin, Springer-Verlag, 1976 pp. 231-4

Faupel $G$ et al: Dynamics of Brain Edema. Edited by Pappus HM, Feindel W, New York, Springer-Verlag, 1976 pp. 337-43.

\begin{tabular}{|c|c|c|}
\hline & Low Dose & High Dose \\
\hline Gobiet & $\begin{array}{c}16 \mathrm{mg} \text { STAT } \\
4 \mathrm{mg} \text { q6h }\end{array}$ & $\begin{array}{l}48 \mathrm{mg} \text { STAT } \\
8 \mathrm{mg} \text { q2h (days } 1 \& 3 \text { ) } \\
4 \mathrm{mg} \text { q2h (days 2\&4) } \\
4 \mathrm{mg} \text { q } 4 \mathrm{~h} \text { (days } 5-8 \text { ) }\end{array}$ \\
\hline Faupel & $\begin{array}{c}12 \mathrm{mg} \text { STAT } \\
4 \mathrm{mg} \text { q6h }\end{array}$ & $\begin{array}{l}100 \mathrm{mg} \text { STAT } \\
100 \mathrm{mg} \text { (after } 6 \mathrm{~h} \text { ) } \\
4 \mathrm{mg} \mathrm{q6h}\end{array}$ \\
\hline
\end{tabular}

Hexadrol $^{\star}$ can be given quickly in high doses One $10 \mathrm{~mL}$ vial contains $100 \mathrm{mg}$ - enough to initiate therapy in these lifethreatening cases. Hexadrol ${ }^{*}$ is already in solution. No breaking of seals or shaking is necessary. And Hexadrol* is so stable it can be stored for up to two years at room temperature.

(dexamethasone sodium phosphate injection U.S.P.)

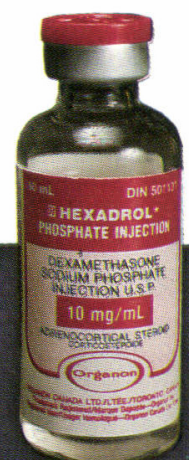


